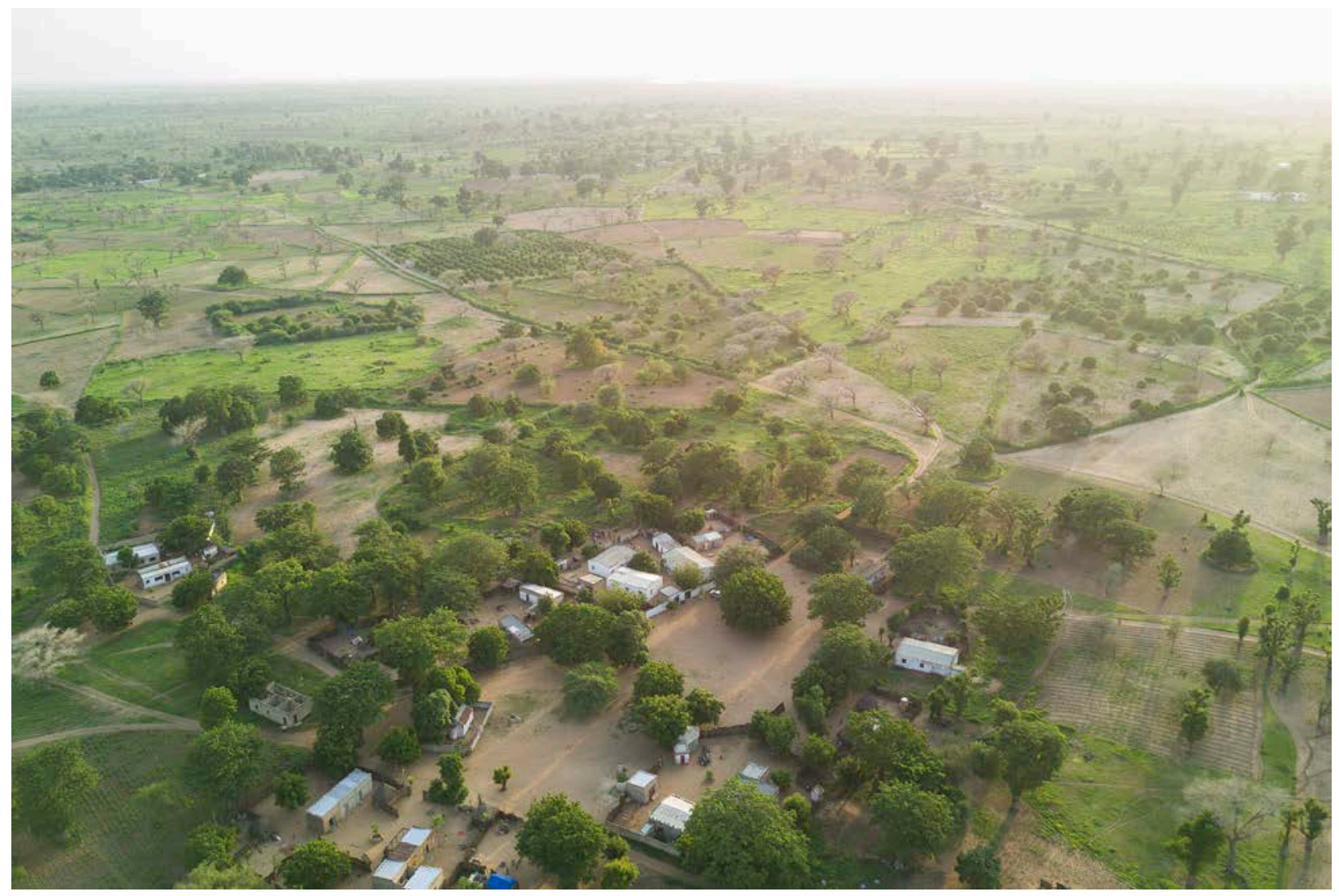

\title{
CUSTOMER AGREEMENT CONSIDERATIONS FOR MICRO-GRIDS IN SUB-SAHARAN AFRICA
}

Eric Lockhart, Samuel Booth, and Ian Baring-Gould National Renewable Energy Laboratory

Technical Report

NREL/TP-7A40-70777

August 2018

A product of the USAID-NREL Partnership

Contract No. IAG-17-2050 


\section{NOTICE}

This work was authored, in part, by the National Renewable Energy Laboratory, operated by Alliance for Sustainable Energy, LLC, for the U.S. Department of Energy (DOE) under Contract No. DE-AC3608GO28308. Funding provided by the United States Agency for International Development (USAID) under Contract No. Contract No. IAG-17-2050. The views expressed in the article do not necessarily represent the views of the DOE or the U.S. Government or any agency thereof, including the United States Agency for International Development.

This report is available at no cost from the National Renewable Energy Laboratory (NREL) at www.nrel.gov/publications.

U.S. Department of Energy (DOE) reports produced after 1991 and a growing number of pre-1991 documents are available

free via www.OSTI.gov.

Cover photo from Xaume Olleros, Power Africa

NREL prints on paper that contains recycled content. 


\section{Acknowledgments}

The National Renewable Energy Laboratory (NREL) thanks Power Africa Beyond the Grid, specifically Katrina Pielli, for invaluable input and feedback. The authors thank Matthew Alcock from Standard Microgrid and Isaiah Lyons-Galante from PowerGen for their review and input, and for permitting us to include excerpts of their customer agreements in this report. Thanks also go to Pepin Tchouate from the Power Africa Transaction and Reforms Program and Abishek Bharadwaj and Peter Weston from Energy 4 Impact. The authors also wish to thank Karen Petersen, Stacy Buchanan, and Britton Marchese from NREL for their contributions. Credit for the cover image (photo of M’Bour, Senegal, taken in 2017) goes to Xaume Olleros and Power Africa. 


\section{Table of Contents}

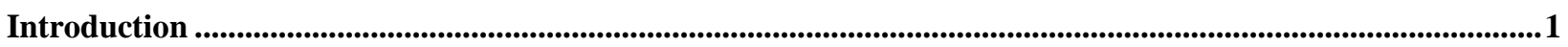

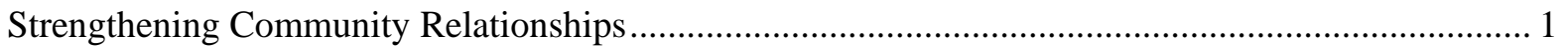

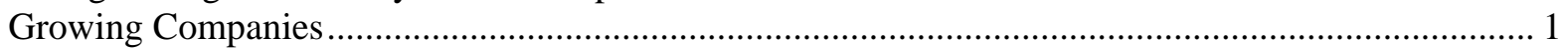

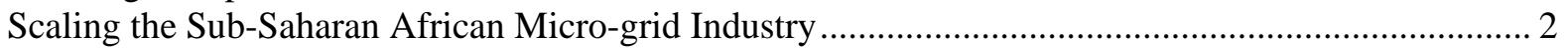

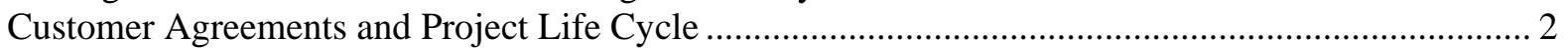

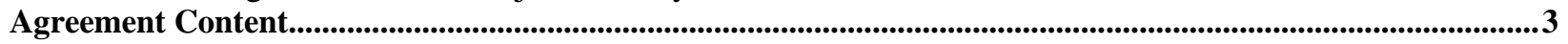

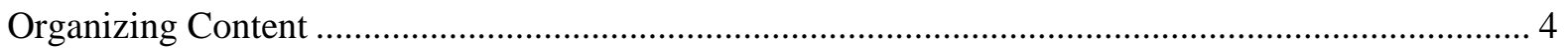

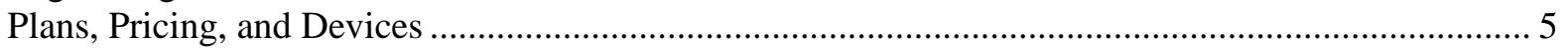

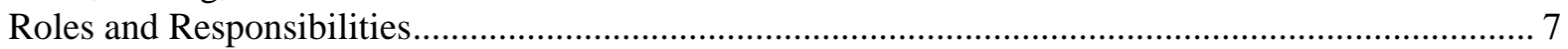

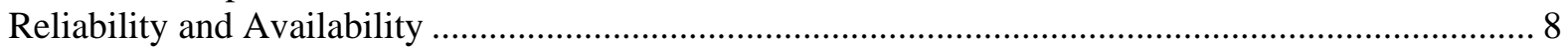

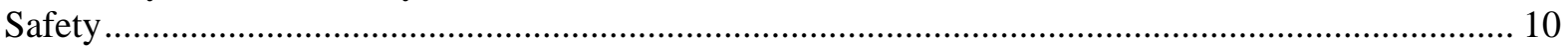

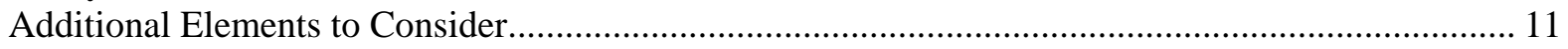

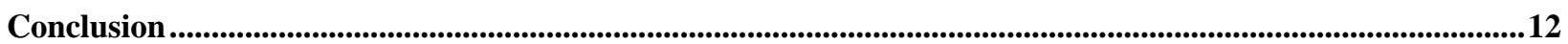

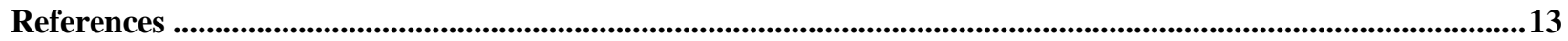

\section{List of Figures}

Figure 1. Market scale requires companies to grow from single experimental systems to larger regional

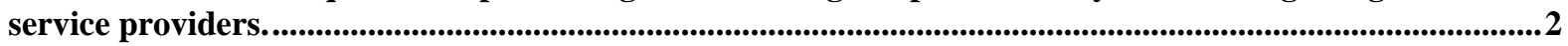

Figure 2. The Customer Agreement serves several different functions during a project lifecycle...........................

Figure 3. Excerpt of Standard Microgrid's graphical plan depiction.............................................................................5

Figure 4. Standard Microgrid's high-level touchpoints with local representative.................................................6

Figure 5. PowerGen mobile money guide excerpt. Illustration from PowerGen ........................................................6

Figure 6. Standard Microgrid pilot project...........................................................................................................

Figure 7. PowerGen troubleshooting guide excerpt ................................................................................................11 



\section{Introduction}

Great strides have been made in electrification over the last two decades, bringing power to roughly 1.2 billion people around the world (IEA 2017). However, an estimated 1.1 billion people-roughly 600 million of whom live in Sub-Saharan Africa—still lack access to modern electricity services (IEA 2017). The majority of electrification gains have been achieved through connection to the main grid. But to reach the next billion people, off-grid solutions will be increasingly necessary-particularly in more remote areas of Sub-Saharan Africa, where grid extension is prohibitively expensive.

Investment interest in micro-grids has been growing among national governments, international donors, and the private sector, but significant barriers to scale remain. In particular, attracting the private capital needed for the industry to scale will require well-understood and scalable business models that provide reliable returns commensurate with the associated risk. Currently, many projects are financed through donor funding, but to take the next step in growth and serve the hundreds of millions of households without access, private debt and equity financing will need to take a leadership role.

This report discusses one dimension of building bankable micro-grid investments: the customer agreement between the developer and the customers the micro-grid will serve. This article draws on the National Renewable Energy Laboratory's (NREL's) experience developing and implementing the Quality Assurance Framework (QAF), which seeks to address barriers to providing reliable and affordable power to remote communities through micro-grid deployment (Baring-Gould et al. 2016). This report is part of a series of articles developed to support implementation of the QAF, along with related developer and country-level technical assistance.

Customer agreements from several active developers ${ }^{1}$ in sub-Saharan Africa, with whom NREL has partnered to implement the QAF, are referenced here to highlight approaches currently being taken. These developers and others in the region have made progress with customer agreement design, but many systems still operate with simple verbal agreements (e.g., "power for two light bulbs and a phone charger is $\$ 5$ per month”). Conversations with stakeholders from government, nonprofits, and the private sector have identified a need for stronger customer agreements that support industry efforts to scale and expand access to modern energy services. The customer agreement's role in scaling spans individual micro-grids, company-level scaling, and industry-wide needs.

\section{Strengthening Community Relationships}

A core part of any business is the relationship with the customer and micro-grids for energy access are no exception. Building trust in rural communities served by micro-grids is particularly important because customers often have limited prior experience with electrification. Furthermore, micro-grids will typically deliver power that is more expensive on a per-kilowatt-hour $(\mathrm{kWh})$ basis than that available to utility gridtied customers in urban areas, so even though micro-grids are often the least-cost option for rural communities, engendering understanding and developing strong relationships to communicate what drives that cost difference will be critical (Reber et al. 2018).

\section{Growing Companies}

As individual developers grow beyond pilot projects to tens or hundreds of micro-grids, effective customer agreements become essential to streamlining organizational systems. Customer management systems that work for a small number of micro-grids can be overwhelming as the number of customers

\footnotetext{
${ }^{1}$ This document typically uses the term developer to represent organizations that own and operate micro-grid power systems. In some cases, a project may be developed (designed and constructed) by one organization and operated by a second organization, an operator.
} 
increases from hundreds to thousands and may include undefined payment conditions and informal complaint reporting infrastructure. Investments in strong customer agreements can engender stronger reporting and internal controls and improve the bottom line through increased retention rates and average revenue per customer. From the perspective of an investor, those improved fundamentals are important, but the customer agreement is also an important platform for understanding corporate risk and business structures.

\section{Scaling the Sub-Saharan African Micro-grid Industry}

Developers coalescing around organizational best practices is key to industry growth. Figure 1 illustrates how business practices can evolve and ultimately drive industry maturation. Effective customer agreements are a critical organizational best practice to move from pilots to scale, yielding benefits for investors, government stakeholders, and the public at large. Investors benefit by increased institutional capacity to understand business models, value projects, and effectively price risks. Government ministries gain better insight into the services micro-grids provide to their customers, which can inform more effective policymaking. Members of the public benefit from the transparency inherent in effective customer agreements and develop trust in the industry's ability to operate with their best interests in mind. Such benefits to each stakeholder group represent important stepping stones towards scaling micro-grid industry development. Most developers are currently in the pilot project stage or the beginnings of regional expansion but achieving scale will be required to achieve energy access goals.

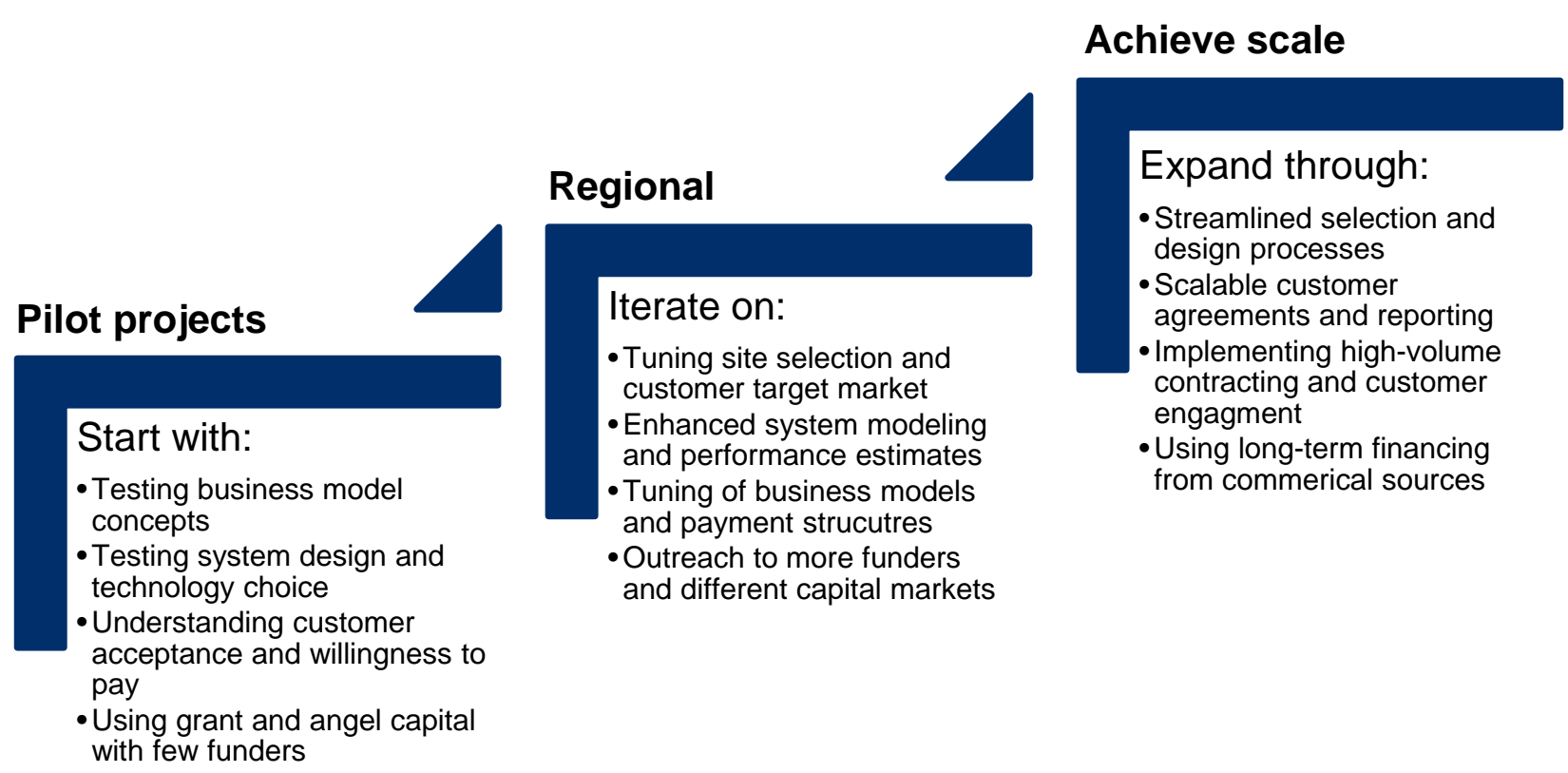

Figure 1. Market scale requires companies to grow from single experimental systems to larger regional service providers. Most developers or system operators are in the pilot phase or the beginnings of regional expansion, but scale is required to achieve energy access goals.

\section{Customer Agreements and Project Life Cycle}

The customer agreement is foundational to the full project life cycle. Well before the developer begins designing a system, the customer agreement is a part of attracting communities to participate in a microgrid and serves as an early introduction to what customers can expect from the system. Once the microgrid is built and operating, the customer agreement anchors effective operations and supports sustainable long-term customer relationships through defined reporting and customer engagement. A rural microgrid, like any utility system, is a business proposition that requires relationships that spans multiple 
decades to be financially successful. The micro-grid is potentially prohibitively expensive to relocate so the micro-grid is permanently tied to that community, though the population or the level of commercial activity may change over time.

High quality service delivery connects the two ends of the micro-grid lifecycle, yet it is always relative to expectations set for the customer at the outset. For example, one developer reported routine challenges with downtime being exacerbated by unrealistic customer expectations that were set in one of the first meetings with the community the micro-grid served. Other developers have described challenges stemming from cases in which micro-grids have been shut down for maintenance and customers stopped paying their bills because they lacked clear and realistic expectations regarding system downtime needs. Figure 2 highlights the ways the customer agreement touches each phase of a micro-grid's lifecycle.

Customer acquisition
System design,

installation,

commissioning
Operations \& maintenance
Decommissioning

\section{Customer relationship spans full project life cycle}

Customer agreement educates prospective

customers and funders; supports system sizing and financing decisions
Customer agreement supports retention and average revenue per customer

Figure 2. The customer agreement serves several different functions during a project lifecycle.

\section{Agreement Content}

This report takes a broad definition of what would be considered a customer agreement, and the concepts described here may be distributed across multiple documents that collectively constitute the agreement between the customer and the developer or system operator. For example, some developers choose to discuss the roles and responsibilities separately from the mechanics of buying and selling energy services. Others may include some of these concepts in the customer agreement and reserve others for a training guide for local representatives who communicate the information to new customers verbally. This report covers key concepts to consider including in customer agreements, but it does not take a position on the ideal format or content given the context-specific nature of that business decision.

At their core, many customer agreements originate from the need to establish a legally binding contract between developers and customers. This report is focused on setting clear expectations about the nature of purchasing electricity from a remote micro-grid; it does not cover how the legal framework in a given jurisdiction might suggest certain inclusions in the core agreement with communities and customers. The legal requirements typically included in customer agreements do, however, create a valuable platform to communicate expectations more broadly, helping to lay the foundation for a healthy relationship between developers and the communities they serve. 
This section begins with a brief discussion of options for organizing content, which is followed by four different categories of customer agreement content:

- $\quad$ Plans, Pricing, and Devices

- Roles and Responsibilities

- Reliability and Availability

- Safety

This section closes with some additional elements to consider, such as system design information or a troubleshooting guide.

\section{Organizing Content}

\section{Content Delivery}

As discussed above, the precise division of elements of the customer agreement across different documents is a business decision, but to the extent that they are included in a single document, a useful approach is combining a "core" agreement that addresses the legal functions of the agreement with a supplement that covers additional details that are critical for effective expectation setting but not legally required. For example, Standard Microgrid has structured its customer agreement to consist of:

- A core agreement that includes the basic terms of plans and pricing

- High-level discussion of roles and responsibilities

- An accompanying supplement that details various plan options, more granular roles and responsibilities

- Basics of the system's design

\section{Designing with Literacy and Numeracy Levels in Mind}

The average level of literacy and numeracy for rural populations served by micro-grids can be lower than that of more urban communities with access to the main grid. This makes it essential to design any agreement for these communities with simplicity in mind, striving to both make the information easier for customers to understand through approaches like diagrammatic representation of processes and easier for developers' local representatives to convey, whether reading the agreement aloud or using it as a reference. Figure 3 is an excerpt of a customer agreement in which Standard Microgrid complemented the descriptions of plan terms with visuals. Figure 4 depicts another element of Standard Microgrid's customer agreement that highlights roles of the local customer representative. 


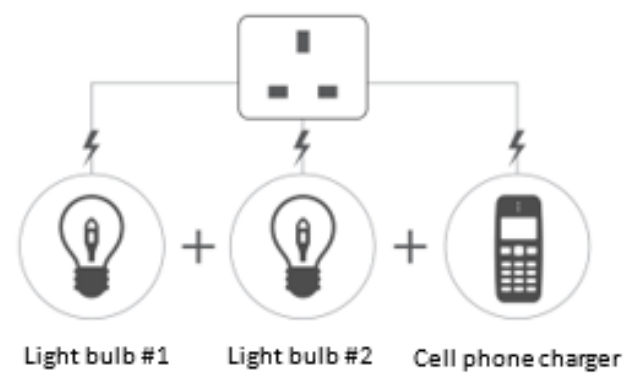

Figure 3. Excerpt of Standard Microgrid's graphical plan depiction. Illustration by National Renewable Energy Laboratory (NREL).

\section{Consider Document Delivery and Availability from the Start}

When developing the customer agreement, careful consideration should be given to how the information will be made available to consumers. For example, documents could be provided in paper copy (that could be lost), posted in public places, or made available through phone texts or be available on the web. Community meetings are good mechanisms to provide information at the start of projects but are not typically appropriate as new customers are signed up or the system expands to include additional services. Training of local staff in customer engagement, given that as the system operates they will likely be the face of the utility to most consumers, and the definition of consumer engagement protocols is likely to be important in maintaining a solid customer relationship.

The remainder of this section covers four core categories of content, followed by a brief discussion of additional elements to consider including.

\section{Plans, Pricing, and Devices}

One of the most important elements of any customer agreement is the section outlining available levels of service and their pricing. Though all agreements will include discussion of the basics, there is an opportunity for improvement by incorporating additional detail on the potential for load growth over time, what goes into determining prices and what may cause them to change, the value of energy efficiency, and what financing options (if any) there are for interconnection and other fees or device purchases.

For simplicity, this discussion focuses on two primary categories of plans to which a micro-grid customer would typically subscribe (though there are a lot of variables within each that need to be parsed and effectively communicated): grid services that generally mimic the flexibility and reliability of the main grid and more limited plans centered around the availability of specific devices at specific times.

\section{Grid-like Service}

Some micro-grids are designed to function like utility grid-tied services with on-demand availability of electricity and billing based on kilowatt-hours of electricity consumed. Though grid-like and generally providing on demand services, there may be differences in costs and anticipated downtime relative to utility, grid-tied power in urban areas. For this reason, there is value in clearly communicating the expectations and reasons for deviation from what communities may know about grid-tied services. While community members may not have direct experience with electrification in their homes, they may have expectations about utility grid services based on travel or the experiences of family members who have migrated to urban areas. A discussion of available levels of service, quality of service, and power system reliability should be clearly expressed so that expectations are maintained. The level of availability and reliability of a specific system is typically technology driven, and thus cost dependent, and should be considered in the initial estimation of community willingness and ability to pay. 


\section{Set Times of the Day and Loads}

Some micro-grid systems or agreements are designed for set levels of service (and/or number of devices) during specific times of day. For example, a customer may sign up to power several light bulbs and a radio for certain periods of the evening. This arrangement offers the benefit of greater certainty for system sizing but also introduces additional complexity to communicate to customers. It is also important for the agreement to clarify how changing the level of service or their time of use would affect pricing, as well as the process, and potential time requirements, to move from one level of service to another. Figure 4 is a depiction of an example of local representative roles in this model of service delivery. Topping up refers to adding additional credit to a customer's account.

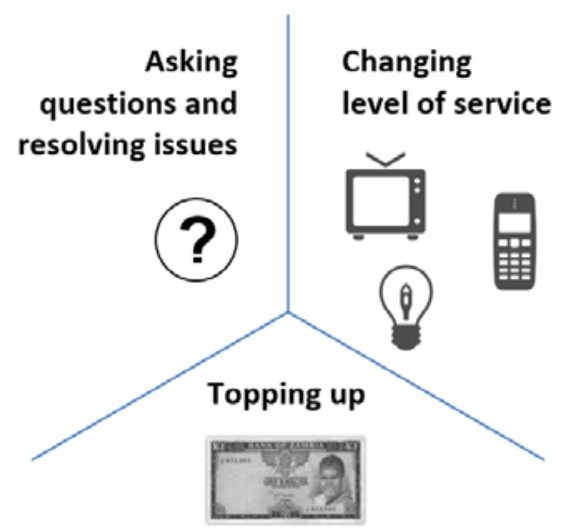

Figure 4. Standard Microgrid's high-level touchpoints with local representative. Illustration by NREL.

\section{Pricing and Payments}

Pricing for energy services and payment mechanisms will typically be included in customer agreements or the suite of documents that go to customers at the inception of a relationship. However, here too there is often room to expand beyond the minimum requirements of communicating the price and billing cycle by including detail about pricing changes over time. For example, developers that work across multiple countries may have a need to change prices over time based on the currency denomination of their financing. There may also be incentives for buying more credit or more time to both save money for customers and provide revenue stability for developers, which can be clearly called out in customer agreements. For systems that leverage mobile money, there may also be value in clearly distinguishing between fees or charges that are charged by the mobile money provider and those that are charged by the micro-grid developers. Figure 5 shows an excerpt of a sample mobile money payment guide from PowerGen Renewable Energy.

\section{$\Leftrightarrow$ PowerGen}

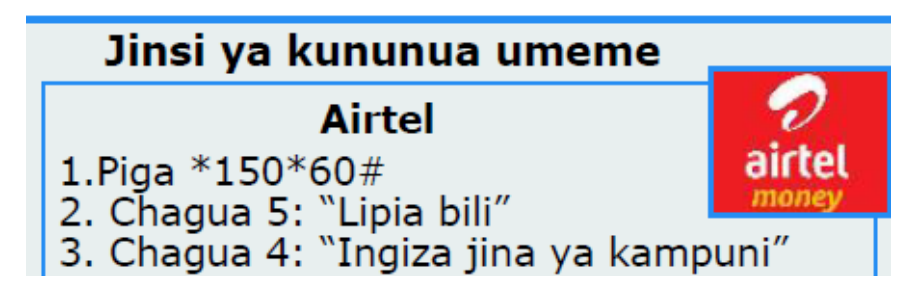

Figure 5. PowerGen mobile money guide excerpt. Illustration from PowerGen 
Customers also need to have clear expectations about whether they are required to pay when they are not using the system, such as with a fixed demand charge for a defined service, and what happens during system downtime because of scheduled or unscheduled micro-grid maintenance.

\section{Devices}

Regardless of the category of plan, communicating clearly about the devices that can and should be used is critical for effective service and satisfied customers. This starts with communicating what can be connected to the micro-grid. Some developers will only allow devices within certain ranges of power ratings to be connected, for example. Starting with a firm understanding of the core requirements and options for devices and communicating what is needed to change devices and what the associated costs will be, is essential to establishing trust and building long-term relationships. Several developers have reported issues with customers acquiring new devices and connecting them to the micro-grid without permission. This can cause technical issues with system power quality. For example, voltage drop to many customers can be caused by the addition of a large load near the end of line and the availability of power for all customers can be impacted if the system does not have excess power available to meet these new loads. Providing context to customers so that they clearly understand why such rules are in place, such as any system power limits, and how choices can impact not only the service to the whole community in terms of lower reliability, but also power cost, may improve community responsiveness.

Discussing devices also provides a useful entry point to educate customers on the value of energy efficiency for systems that charge on a per kWh basis (as opposed to per device). In that instance, from the customer's perspective using energy efficient devices will maximize the value of each dollar spent, something that has been demonstrated to lower the capital cost, and thus levelized cost of a micro-grid power system. Customers who are getting the most out of their purchased electricity translate to a customer satisfaction benefit for developers. Despite the benefits on both sides, there are barriers to integrating energy efficiency into purchasing decisions because of a lack of understanding of concepts such as levelized cost of energy. Developers can begin to address these by effectively integrating information about the benefits of energy efficiency into the customer agreement at the outset.

\section{Roles and Responsibilities}

Clear roles and responsibilities serve as the foundation for relationships between representatives of system operators and customers. Though most customer agreements include the basics on the responsibilities to buy and sell electricity, clearly outlining broader roles and responsibilities of a diverse set of stakeholders serves as another opportunity to build trust and prevent misunderstandings before they arise. The main parties to consider for a customer agreement are customers, operators of the micro-grid, and typically regulators in the power sector. There may be other stakeholders that are relevant to include, such as third-party vendors or mobile money service providers, but these are not explicitly included in this document.

\section{Customers}

The customers will have common responsibilities, such as buying electricity and reporting issues with power quality, availability, and reliability. Customers may also have specific requirements about in-home wiring and, as discussed above, can be required to inform the system operator about the addition of new or unusual loads. One critical issue that should be clearly articulated is how a customer should respond to common issues; for example, some system operators prefer that customers assess the situation and take basic measures (such as flipping circuit breakers), while others prohibit customers from interacting with any element of the power system beyond their devices. The specific requirements will depend on the business model of the system operator, the community, and system design. The customer should also be informed on how customers should contact the appropriate government authority if they feel that the operator is not meeting the agreed upon level of service and what specific response should be expected. If 
there are specific actions that could cause safety issues or a loss of service, such as poor in-house wiring, or the termination of service, these should be identified along with the steps required to reinstate service and what appeal process may be available.

The terms and conditions for terminating a connection or account straddle customer and developer/operator roles and responsibilities. It is important for customers to understand what they need to do in order to disconnect from the system. The customer agreement should also clearly delineate under what circumstances the developer/operator can or will disconnect customers (such as for non-payment or improper usage).

\section{Developers/Operators}

Developers and system operators will have a broader suite of responsibilities, from designing, installing and maintaining the system to responding to customer concerns and monitoring system performance. Customer agreements should provide specific expectations of the developers, such as any defined levels of service, reporting requirements, and how specific customer complaints will be addressed or mitigated. There may be value in parsing the roles of remote business staff (e.g., those responsible for remote monitoring, billing), local representatives (e.g., staff in each community responsible for customer relations and potentially early system troubleshooting), and technical staff (e.g., those responsible for handling technical issues or performing equipment maintenance and replacements).

\section{Regulatory Body/Government}

The government will play a role in regulating and, in many cases, encouraging micro-grid deployment. Electricity service is commonly considered a public service to varying degrees and there may be value in detailing what is in the developer's control and what is required by the relevant regulatory body. For example, national or regional regulations may create constraints or requirements for tariffs that are important to share with customers to calibrate expectations and direct complaints. The government may also have reporting requirements or installation codes and standards that inform design decisions.

It will be important to clarify where and how customers should air complaints and which entity will respond and reconcile issues across the different levels of developer staff and local, regional, and national government representatives. For example, payment challenges and power quality issues might be addressed by different parts of an organization, and issues related to high tariffs might be more appropriately addressed by government representatives. The next section on reliability, availability, and quality proposes a framework for setting expectations that may also be appropriate to incorporate in developer responsibility documentation.

\section{Reliability and Availability}

Effectively communicating about system reliability is a critical function of a customer agreement. Many customers will be experiencing consistent electricity access for the first time, though they may have experience with the main grid in cities and other prepaid products (such as cell phone service). It is important to clearly communicate when, why, and how often customers should expect the system to be down. In certain settings it may also be valuable for system operators to report on those service metrics to customers on a regular basis.

The Quality Assurance Framework consists of three categories of metrics for micro-grid developers and system operators to consider using in order to set clear expectations for system performance. 


\section{Power Quality}

Power quality addresses the provided power's ability to safely serve customer needs. For example, if a household is contracted to be able to power a television, this metric refers to the micro-grid's ability to provide electricity of sufficient quality to safely power the TV over time.

\section{Power Availability}

Power availability refers to the level of power and energy available and seeks to measure the micro-grid's ability to satisfy instantaneous power needs and a given duration of necessary power levels (energy delivered) that meets customer needs and expectations.

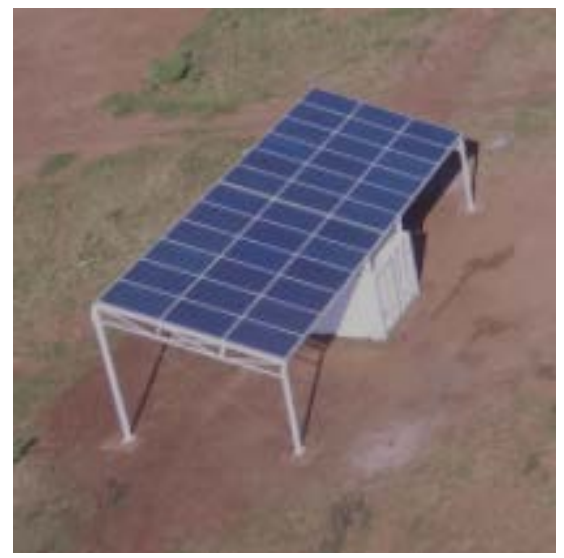

Figure 6. Standard Microgrid pilot project. Photo from Standard Microgrid.

\section{Power Reliability}

Power reliability is a measure of the amount of time the system is capable of providing energy services under normal or abnormal conditions, sometimes referred to as "uptime”. There are several ways to measure power reliability, but two helpful categories for isolated power systems that use variable renewable technologies may include planned and unplanned downtime. Planned downtime may be based on known maintenance requirements, such as periodic battery testing or service for which the power system may be offline, or due to resource-driven downtime, in which the system is designed to operate with a defined amount of storage and there is a specific chance per year that a longer absence of renewable energy would be possible based on system modeling. Unplanned downtime could be the result of equipment failure, a lack of fuel supply, or other issues outside of general operational considerations. Planned and unplanned outages can be further subdivided into the frequency of downtime (e.g., number of times the system is down per year) and the duration of downtime (e.g., average number of hours or days the system is down per outage). This results in four categories to consider reporting on:

- Unplanned system interruption frequency

- Unplanned system interruption duration

- $\quad$ Planned system interruption frequency

- Planned system interruption duration.

Each of those indicators can be measured in absolute terms, relative to expectation or a performance commitment, and as a percentage of a time period (e.g., percentage of the year that the system is down). The planned reliability dimension is likely the aspect of reliability that will be most directly experienced by customers on an ongoing basis whereas the unplanned categories are more about assessing system 
operation and performance. As a result, there may be value in parsing those different types of downtime in the customer agreement to properly calibrate expectations and avoid undue frustration with planned and unplanned downtime.

Legal considerations are outside the scope of this report, but it is important to note that power reliability may be one of the more sensitive legal and payment-related issues in the customer agreement and directly relates to consumer perception of a power system and its value. If consumers expect and are being discounted to allow a high amount of planned downtime, they will continue to think more favorably of the power system as compared to consumers who have expectations of a higher power reliability. One approach is to frame reliability in terms of the goals of the micro-grid developer, such as striving for 95\% power availability on an annual basis rather than contractually committing to that level. This can help set expectations but avoid creating a scenario where recourse for shortcomings would be expected. In other words, setting a goal does not necessarily require recourse if it is not met. It should also be noted that if there is an expectation of a specific level of reliability, then the micro-grid operator should have the means, through some form of monitoring and recordkeeping, to demonstrate what the actual reliability is.

\section{Safety}

The system operator will typically be responsible for safety related to the micro-grid. The customer agreement is a useful venue to highlight good safety practices that a developer has put in place as well as the ways in which customers can contribute to safety. This section will speak to some of the activities or behaviors that could fit in each category.

\section{Customer}

The customer's responsibilities to maintain a safe micro-grid could include:

- Only connecting approved devices

- Not tampering with central components of the system

- Notifying the system operator in a timely fashion when there are issues with the system.

\section{System Operator}

There are many more safety responsibilities for the system operator, and it may not make sense to delineate all of them, but there may still be value in communicating the shared nature of successfully maintaining a safe micro-grid and further contextualizing the differences between a micro-grid and gridparity services. Noting things like safety around batteries, switch gear, and DC wiring (if applicable) also communicates the dangers associated with each to further discourage customers or unqualified technicians from interfering with the system and putting themselves in danger. A few examples include, but are not limited to, the following:

- Ensuring power system and component safety, e.g., controlled site access, proper signage, and appropriate enclosure ventilation (if applicable)

- Practicing lock-out tag-out while performing system maintenance

- Wearing appropriate protective equipment and only conducting work with the proper training and supervision

- Performing periodic visual inspections of system components

- Performing remote system monitoring for faults and failures (if applicable) 
- Noting practices or procedures to follow in response to events such as a lightning strike or downed power line or pole.

\section{Additional Elements to Consider}

This discussion should be considered a menu of options-the priorities and varying levels of detail and attention that each option receives are ultimately business decisions that depend on both the developer or system integrator and the context in which they are working.

\section{System Design}

In some settings it may also be valuable to include high-level detail about the system design in the customer agreement. For example, if a community is electrified using a system composed of a solar array and a battery bank, it may be helpful to educate community members on the underlying system so they can better understand requirements for maintenance-related downtime or establish expectations for rare unplanned downtime resulting from an unanticipated number of days in a row of decreased solar output. This element of the customer agreement could be included in the appendix and be as simple as a graphic or photo showing the equipment.

For systems that have strict requirements for who interacts with central components, it may also be beneficial to clearly illustrate which components power the micro-grid. For example, at least one operator refunds customers for downtime from regular equipment issues but does not issue refunds if the equipment is down because it has been tampered with (even if not maliciously) by anyone in the community. The purpose of that provision is to encourage community supervision of the micro-grid, but in this case that element of the business model is enhanced by effective education about the system.

\section{Troubleshooting Guide}

Another addition to consider is a troubleshooting guide that reviews what to do in the event of an outage. The basics of roles and responsibilities will likely already be included but pulling those pieces together into a decision tree that clearly outlines what to do can help parse the different types of challenges, clarify expectations for customers, and potentially save operators costs stemming from household or community visits. One micro-grid operator has taken this approach by creating a troubleshooting guide that walks through the steps to take when there is an outage, including checking to see if neighbors have power and confirming that a customer has sufficient credit (see Figure 7).

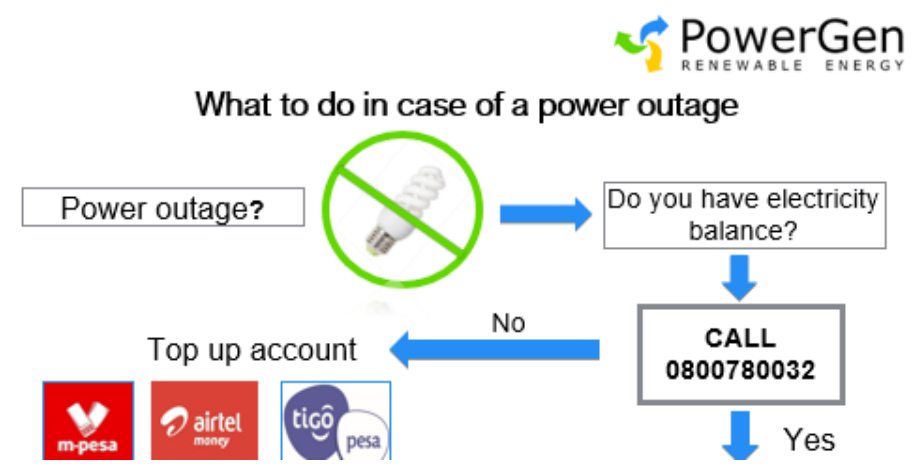

Figure 7. PowerGen troubleshooting guide excerpt. Illustration from PowerGen. 


\section{Conclusion}

Micro-grid deployment at a large scale will be necessary for achieving ambitious national and international electrification goals and reaching communities for whom grid extension is prohibitively expensive. The micro-grid industry is growing to fill this need, but barriers remain to reaching scale with sustainable, bankable business models. An important step along the way to industry maturation is creating customer agreements that serve as a foundation for a healthy, long-term relationship between developers, operators, and the communities their micro-grids serve. In addition to directly setting clear expectations with customers, a strong customer agreement can be a valuable tool for prospective funders, system sizing discussions, and customer retention. This report covers considerations for customer agreement design and content and is intended to serve as a resource for micro-grid developers seeking to develop or re-design customer agreements to support growth and help achieve scale. 


\section{References}

Baring-Gould, Ian, Kari Burman, Mohit Singh, Sean Esterly, Rose Mutiso, and Caroline McGregor. 2016. Quality Assurance Framework for Mini-Grids. NREL/TP-5000-67374. Golden, CO: National Renewable Energy Laboratory. https://www.nrel.gov/docs/fy17osti/67374.pdf.

International Energy Agency (IEA). 2017. Energy Access Outlook 2017: From Poverty to Prosperity. Paris, France: International Energy Agency. http://www.iea.org/access2017/.

Reber, Tim, Sam Booth, Dylan Cutler, Xiangkun Li, and James Salasovich. 2016. Tariff Considerations for Micro-grids in Sub-Saharan Africa. Golden, CO: National Renewable Energy Laboratory. https://www.nrel.gov/docs/fy18osti/69044.pdf. 


\section{www.nrel.gov/usaid-partnership}

\section{USAID}

United States Agency for International Development 1300 Pennsylvania Avenue NW • Washington, DC 20523 $+1-202-712-0000$

www.usaid.gov

\section{Katrina Pielli}

Senior Energy Advisor and Lead, Beyond the Grid USAID | Power Africa

Pretoria, South Africa

Office: +27 12-452-2086 | Mobile: +27 72-710-5162

www.usaid.gov/powerafrica | kpielli@usaid.gov

\section{ONREL}

National Renewable Energy Laboratory

15013 Denver West Parkway • Golden, CO 80401

$+1-303-275-3000$

www.nrel.gov

\section{Samuel Booth}

Senior Project Leader, Microgrids

National Renewable Energy Laboratory (NREL)

Office: +1-303-275-4625 | Mobile: +1-303-513-6786

www.nrel.gov | Samuel.Booth@nrel.gov

NREL is a national laboratory of the U.S. Department of Energy, Office of Energy Efficiency \& Renewable Energy, operated by the Alliance for Sustainable Energy, LLC.

NREL/TP-7A40-70777 • August 2018 